nephron

Practice
Nephron 2017;135:6-14

DOI: $10.1159 / 000448627$
Received: November 5, 2015

Accepted after revision: July 20, 2016 Published online: September 7, 2016

\title{
A Pilot Randomized Controlled Trial to Promote Immunosuppressant Adherence in Adult Kidney Transplant Recipients
}

\author{
Daniel Cukor ${ }^{a, c}$ Nisha Ver Halen ${ }^{a, c}$ Melissa Pencille ${ }^{c}$ Fasika Tedla $^{b}$ \\ Moro Salifu ${ }^{b, c}$ \\ ${ }^{a}$ Department of Psychiatry and Behavioral Science, and bepartment of Medicine, SUNY Downstate Medical Center, \\ 'Brooklyn Health Disparities Center, Brooklyn, N.Y., USA
}

\section{Key Words}

Kidney transplant $\cdot$ Immunosuppressive therapy ·

Randomized clinical trial

\begin{abstract}
Background: Nonadherence to immunosuppressant medication is a prevalent practice among kidney transplant recipients and has been associated with increased risk for graft failure and economic burden. The aim of this pilot study was to test whether a culturally sensitive cognitive-behavioral adherence promotion program could significantly improve medication adherence to tacrolimus prescription as measured by telephone pill counts among kidney transplant recipients. Methods: Thirty-three adult transplant recipients were less than $98 \%$ adherent to tacrolimus prescription based on 3 telephone pill counts and were randomized either to the 2-session cognitive-behavioral adherence promotion program or to standard care. The curriculum was developed from an iterative process with transplant recipients into a 2-session group program that provided psychoeducation, addressed barriers to adherence, fostered motivation to improve adherence behavior, and discussed cultural messages on adherence behavior. Results: The intervention group displayed significantly higher levels of adherence when compared to the control group $(t=2.2, p=0.04)$ and.
\end{abstract}

similarly, when the amount of change was compared between the groups, the intervention group showed more change than the control condition $(F(22,1)=12.005, p=$ 0.003). Tacrolimus trough concentration levels were used as a secondary measure of adherence and, while there were no significant between-group differences for mean trough concentration levels, the variability in the trough levels did significantly decrease over time indicating more consistent pilltaking behavior in the intervention group. Conclusions: There is preliminary support for the pilot program as a successful intervention in helping patients with their immunosuppressant medication.

(c) 2016 S. Karger AG, Basel

\section{Introduction}

Poor adherence to medication regimens accounts for substantial worsening of disease, death, and increased health care costs in the United States [1-3]. Lower adherence to immunosuppressant drugs has been associated with increased costs [4], decreased graft survival $[5,6]$, and higher rates of mortality [7, 8]. Kidney graft recipients who are nonadherent to their immunosuppressive medications are at an increased risk of infection, acute rejection episodes, chronic rejection, and ultimately graft

\section{KARGER}

(c) 2016 S. Karger AG, Basel

E-Mail karger@karger.com

www.karger.com/nef
Dr. Daniel Cukor

Department of Psychiatry and Behavioral Science

SUNY Downstate Medical Center

450 Clarkson Avenue, Brooklyn, NY 11203 (USA)

E-Mail daniel.cukor@ downstate.edu 
failure $[9,10]$. Despite increased risk for negative consequences, nonadherence is more common among kidney transplant recipients [11], with reported rates of nonadherence ranging from 5 to $68 \%[12,13]$.

Several studies have identified patient characteristics associated with nonadherence to immunosuppressant medications in transplant recipients, with mixed evidence indicating that racial/ethnic minority groups are less adherent [14-26]. The reasons for these racial disparities in renal transplant recipients are unclear but are probably multifaceted [27].

Patient's perception of the perceived risks and benefits of following medical advice has been posited as a key factor in predicting behavior by the Health Belief Model (HBM). The HBM has been used in a variety of contexts, including adherence to medical prescription [28]. Perceived barriers and benefits are consistently the strongest predictors of the broad array of health behaviors in a variety of medical populations [29] and specifically to adherence behaviors [30]. Resnicow's model of cultural sensitivity similarly emphasizes the importance of understanding how members of a target population perceive their illnesses in order to modify health behaviors and this model has been used to guide the development of various health-promoting interventions $[31,32]$. Therefore, the identification of salient barriers to medication adherence in a particular population is vital to the development of targeted adherence interventions.

Several barriers to taking immunosuppressant medication in renal transplant patients have been previously identified [33]. In our previous work [34], we found that there were different pathways to nonadherence, with some people acknowledging that they deliberately chose not to take their medication (e.g. because of side effects) and others identifying barriers that were beyond their control (e.g. inadequate finances). Both types of barriers were associated with increased nonadherence. We have also demonstrated an association between depression and survival and posited that this relationship may be mediated by various psychological and physiological factors, with treatment nonadherence representing one potential pathway. Depressive symptoms of low motivation, impaired concentration, and apathy may well significantly interfere with patients' adherence to treatment for endstage renal disease [35].

In reviews of medication adherence promotion interventions in mixed medical populations, the most successful methods include combinations of behavioral interventions and reinforcements in addition to providing educational information about the patient's condition and the treatment [36-38]. Few studies have systematically tested behavioral interventions in renal transplant patients. In a study of adult renal transplant recipients, medication nonadherence was higher for participants in the control group compared to those who received an education/ counseling intervention [39]. In a small pilot randomized controlled trial (RCT), investigators tested the efficacy of an educational and behavioral group intervention in the reduction of nonadherence as measured by MEMs caps. While the intervention group had greater improvement in adherence at the end of the intervention as compared to a standard care group, these effects did not reach statistical significance and both groups returned to pre-intervention nonadherence levels at the end of the 6-month follow-up [40]. In a more recent study, 15 adult renal transplant patients were randomly assigned either to a continuous self-improvement intervention or to an attention control group. The study concluded that participants receiving the self-improvement intervention had significantly higher electronically monitored medication adherence scores as compared to the control group [41].

As suggested by Russell [42], there is a need for the cultural adaptation of transplant intervention in minority populations, so in preliminary work for this study, we gathered survey data and held focus groups to better understand Black kidney transplant recipients' and health care providers' perceptions of the most salient motivations and barriers to immunosuppressant adherence. Fifty patients over the age of 18 years who had undergone kidney transplantation not less than 6 months prior were asked to complete a survey (Immunosuppressant Therapy Barriers Scale) [43] (fig. 1) and some $(\mathrm{n}=10)$ were available to further answer questions about the key benefits and barriers to adherence. Similarly, a group of health care professionals $(\mathrm{n}=5$; transplant nephrologists, transplant coordinators) also provided input around their perception of key barriers to immunosuppressant adherence and parameters for the intervention programs. The extent of development of the current adherence promotion study was evaluated based on the feedback obtained. As an example, based upon patients' feedback, the decision was made not to include conditions that require any form of deception, as there were high levels of mistrust in clinical research. Consequently, the study assessments were blinded, but participants would not be subjected to placebo treatment.

The primary aim of this study was to pilot a culturally sensitive adherence promotion program for kidney transplant recipients who were less than ideally adherent to immunosuppressant prescription. We sought to examine whether exposure to an adherence promotion program 




Fig. 1. Percent of sample endorsing as a substantive barrier.

would result in improved medication adherence (specifically in terms of taking and being persistent [44]) as compared to standard care provided by the nephrology treatment team.

\section{Methods}

This RCT was designed to pilot the culturally sensitive adherence promotion program that was developed using information gathered from our preliminary surveys and focus groups with transplant patients and providers. Inclusion criteria for the study included kidney transplant patients with a current prescription of daily tacrolimus, over the age of 25 , and less than $98 \%$ adherence to medication prescription, as determined by 3 baseline pill counts (described below). Tacrolimus (FK506, Prograf ${ }^{\circledR}$ ) is an immunosuppressant drug that has emerged as the gold standard for the prevention of graft rejection following kidney transplantation. Exclusion criteria were lack of telephone to complete pill counts and lack of English proficiency to participate in adherence-promotion sessions. English proficiency was assessed based on the participant's ability to answer screening questions and questionnaires administered in English.

\section{Measures}

Adherence Measurement

Primary - Phone Pill Counts. While there are a variety of direct [45] and indirect techniques [1] to measure medication adherence, there are relative advantages and disadvantages to the various assessment types, balancing accuracy, cost, and burden [46]. Ultimately, it was decided not to rely on the commonly used electronic monitoring caps, as there is evidence that they can alter medication-taking behaviors [47]. An alternative strategy to measuring adherence is in-person pill counts. However, the burden of this type of measurement is high [48]. Telephone-pill counts have been examined as an alternative to in-person pill counts in a variety of medical populations [45, 49-52]. Kalichman et al. [50, 51] found that unannounced telephone pill counts paralleled the ability of office-based and home-based pill counts to measure adherence to antiretroviral medication (with an interclass correlation coefficient between phone and home pill counts of.997, $p<0.001$ ) while also mitigating the logistical challenges that encumber office- and home-based visits. Thus, we selected this method of adherence measurement, as the pill count methodology is not specific to the type of pill or disease being studied.

Participants were contacted for 3 pre- and post-intervention telephone pill counts. At each call, the research assistant (RA) instructed the participant to count all of their tacrolimus pills over the phone using a pill tray that was provided by the study. The count was repeated a second time to ensure accuracy. If there was discrepancy, pills were recounted until 2 consecutive counts agreed. The RA recorded the current pill count, prior pill count, and number of prescriptions filled. This allowed the RA to inquire about any possible change in the medication regimen. Using this information, an adherence percentage was calculated for each pill count. Due to the possible emergent consequences of extreme nonadherence, if the participant reported skipping 3 consecutive days, the treating physician would be contacted for follow-up and study participation ended.

Adherence percentage was determined by calculating the difference in 2 pill phone counts over the expected numbers of pills to be taken, given the length of time between the counts (pill count 2 - pill count $1 /$ expected number of pills). Two adherence percentages were averaged to form a baseline measure of adherence. Similarly, 3 additional pill counts at follow-up were conducted, yielding 2 adherence percentage scores, which were then averaged.

Secondary - Tacrolimus Trough Concentration Levels. Tacrolimus whole-blood samples used for the determination of $12 \mathrm{~h}$ tacrolimus trough concentrations were collected as part of the patient's usual clinical care. Trough concentrations have been found to correlate well with area under the concentration-time curve measurements in kidney transplant recipients $(\mathrm{r}=0.91-0.99)$ [53]. Thus, trough concentrations are a good index of overall drug exposure and are currently used for routine monitoring as part of patient care post transplantation. Blood for trough concentration 
Fig. 2. Participant flow.

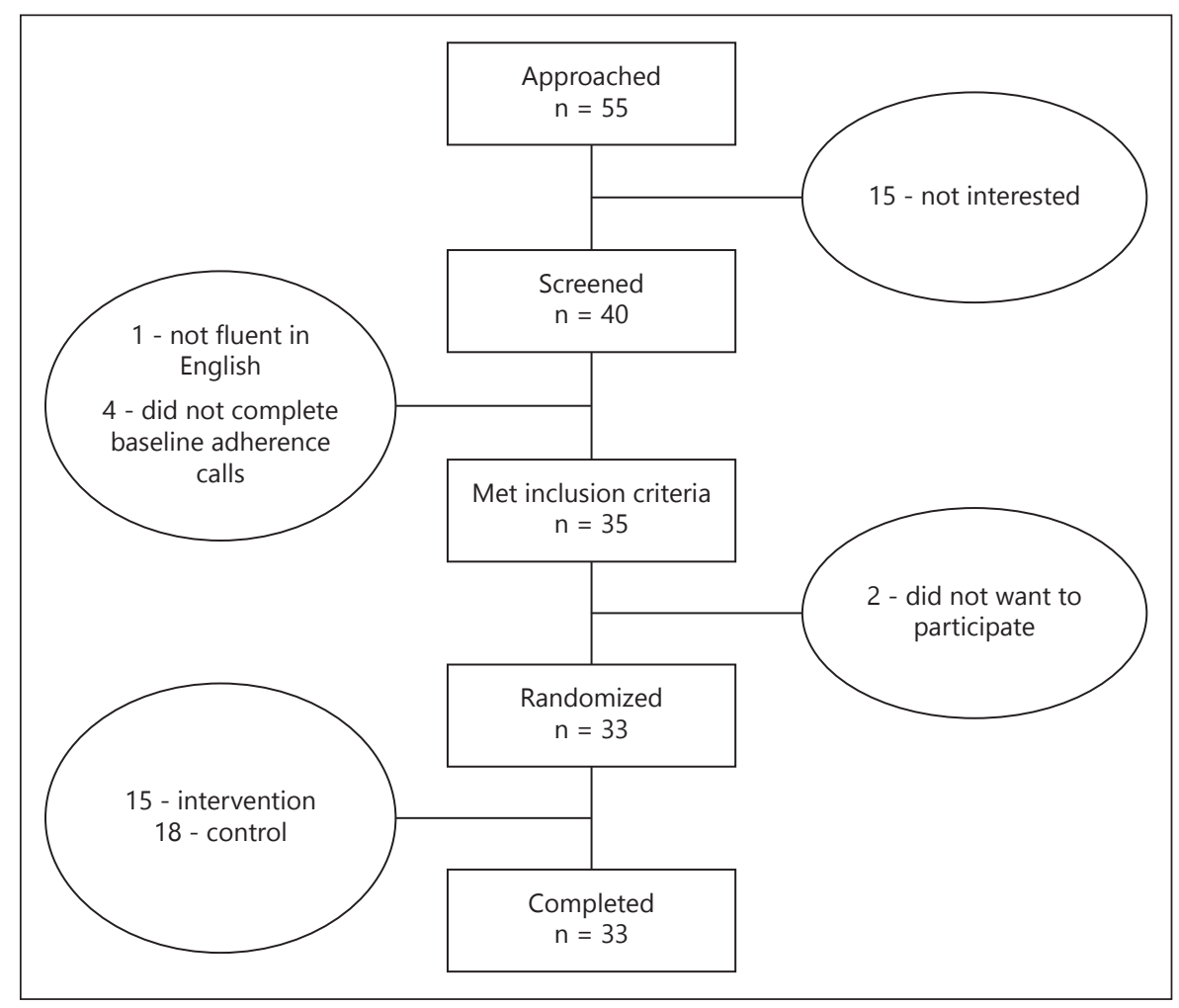

measurements was collected before the morning dose. Tacrolimus concentrations were determined by the high-performance liquid chromatographic method.

Psychological Functioning Measurement

Beck Depression Inventory-II (BDI-II). The BDI-II is a 21 -item self-report instrument with high scores (range 0-63) reflecting the presence and severity of depressed mood [54]. Depressed mood was assessed to measure psychological functioning of our sample.

\section{Study Procedures}

Patients were approached in the waiting room of the transplant clinic and asked to complete a 10-minute screen for potential eligibility. This assessment included measures of self-reported adherence, depression, and sociodemographics. Patients were approached consecutively until desired recruitment was reached.

Within one week of completing the in-office baseline measures, eligible participants were contacted for an initial telephone pill count. Participants were then contacted twice within 4 weeks to complete a second and third unannounced telephone pill count. The 3 pill counts were used to calculate a baseline medication adherence percentage, which was used to determine the eligibility for the intervention phase of the study. If the participant demonstrated an average of less than $98 \%$ adherence across calls, they were considered eligible for the intervention and were randomly assigned using a 1:1 random number allocation strategy to either the treatment condition or the standard care condition. Randomization was done through random number sequences generated (no blocks) before the study began. The person doing the randomiza- tion kept the information confidential from the independent assessor, and participants were instructed not to share their group assignment with the assessor.

This stringent adherence cutoff was selected based on the input from focus groups. It has been demonstrated that even minor nonadherence to immunosuppressant medication can affect maintenance of a transplant organ [55]. Specifically, there is evidence from previous research that shows that minimal deviations from the prescribed regimen were associated with increased risk of graft rejection in renal transplant recipients [55-58]. Beginning 6 weeks after randomization, all participants were contacted biweekly to complete 3 additional follow-up telephone pill counts. During the final telephone call, participants were asked to complete a brief post-treatment assessment. Participants received $\$ 5$ for completing the baseline assessment, post-treatment assessment, and for each completed telephone pill count. Participants were not compensated for their time at the adherence-promotion sessions, but lunch and transportation costs were provided.

In total, 55 kidney transplant recipients were approached for participation while waiting for their medical appointments. Forty individuals agreed to undergo the phone pill count to determine eligibility. No information was collected about those who did not participate. Of these, baseline adherence level was collected on 35 (i.e. participated in phone counts). All of them were eligible to participate (adherence $<98 \%$ ) and 33 agreed to be randomized (fig. 2). All randomized participants completed the study. No participants in either condition reported 3 consecutive days of skipped doses, and consequently, no one's participation was terminated early. Data were collected from January to December 2011. There were no changes to the study procedure during the course of the study. 
Table 1. Small group intervention components

\begin{tabular}{ll}
\hline Component & Description \\
\hline Psychoeducation & $\begin{array}{l}\text { Addresses the difference between compliance and adherence, the role of side effects in } \\
\text { choosing not to take medication, physician mistrust, over-prescription of medication, } \\
\text { and safety of medication - targets HBM's constructs of perceived susceptibility and } \\
\text { perceived severity }\end{array}$ \\
\hline Barriers & $\begin{array}{l}\text { Identification of specific barriers to adherence with particular emphasis on maintaining } \\
\text { adherence despite limited resources - targets HBM's constructs of perceived barriers }\end{array}$ \\
\hline Motivational interviewing & $\begin{array}{l}\text { Exploring readiness for change and motivation to improve adherence behavior - targets } \\
\text { HBM's constructs of perceived barriers and benefits }\end{array}$ \\
\hline Behavior modification & $\begin{array}{l}\text { Utilizing behavioral modification to develop strategies to address personal barriers - directly } \\
\text { targets HBM's construct of health behavior activity }\end{array}$ \\
\hline Affect awareness & $\begin{array}{l}\text { Increasing awareness of impact of mood on adherence behavior - targets HBM's constructs } \\
\text { of cues to action }\end{array}$ \\
\hline Cultural tailoring & $\begin{array}{l}\text { Impact of group and cultural messages on adherence attitudes and behaviors - targets HBM's Week 2 } \\
\text { constructs of perceived threat }\end{array}$ \\
\hline
\end{tabular}

\section{Treatment Arms}

Intervention Condition

The treatment condition consisted of a 2-session group intervention that was initiated within 2 weeks of randomization. Between 4 and 6 participants were invited to participate in a group. The sessions were each $2 \mathrm{~h}$ long and were held in an outpatient office suite. Three separate groups of participants completed the 2 -session intervention and sessions were held between one and 2 weeks apart.

\section{Intervention}

Our adherence promotion intervention incorporated techniques derived from cognitive behavioral therapy (CBT) and motivational interviewing (MI) techniques. CBT is a short-term, focused psychotherapy used in the treatment of a wide range of psychological and behavioral issues. The focus of the intervention is on how one thinks, behaves, and communicates in present time, as opposed to a focus on one's early childhood experiences. The intervention is action-oriented, practical, rational, and helps the patient gain independence and effectiveness in dealing with real-life issues [59-61]. MI is a client-centered, semi-directive method of engaging intrinsic motivation to change behavior by developing discrepancy as well as exploring and resolving ambivalence [6264]. MI is nonconfrontational and attempts to increase the patient's awareness of the potential problems caused, consequences experienced, and risks faced as a result of the behavior in question and seeks to help patients consider what might be gained through change.

Standard CBT interventions for nonadherence were modified and adapted for (1) the particular challenges associated with being a transplant patient and (2) the cultural needs and African American patients receiving transplant services.

Information gathered from preliminary focus groups was integrated and resulted in a small-group intervention that included the components described in table 1 . The intervention was administered by doctoral level psychologists (DC and NVH).

\section{Control Condition}

Participants in the control condition completed the same number of unannounced telephone pill counts at the same intervals as participants in the intervention condition. They did not receive any additional information or intervention regarding their adherence behavior outside of standard care, which involved monthly appointments with the nephrology transplant treatment team to assess kidney functioning and address any issues presented by the provider or the patient. This treatment as usual plus monitoring condition was selected as the appropriate control for several reasons. Due the pilot nature of the trial, patient feedback about the undesirability of sham placebo conditions, and the limited sample size, having 2 active treatments would have surpassed our power estimates [65]. Furthermore, there has been scant evidence that behavioral intervention is effective in this population and any attention-matched control would in essence be another active treatment arm. Finally, while there is increased threat to internal validity by using a treatment as usual condition, there is greater ecological validity in that this represents standard clinical practice.

\section{Statistical Analyses}

We used the Statistical Software Package of Social Science (SPSS, IBM, Chicago, Ill., USA) version 21.3 to conduct analyses. Demographic and clinical variables were expressed, as appropriate, as frequencies, mean, and SDs. We used intention-to-treat principles for analysis. To test whether adherence levels differed between the study groups at baseline and outcome, we created an adherence score by averaging the 3 baseline pill count data and then the 3 follow-up pill count data. Statistical significance was set at $\mathrm{p}<0.05$.

We used chi-square analyses to assess differences between groups in all categorical variables and t tests were used to compare differences between groups on continuous variables. Outcome data were similarly compared using t tests to evaluate mean differences between groups. Linear regression modeling was used to determine within group changes for both the intervention and control conditions. 
Table 2. Sample descriptive characteristics, mean \pm SD (range)

\begin{tabular}{lcccc}
\hline & Total sample & Control condition $(\mathrm{n}=18)$ & Intervention condition $(\mathrm{n}=15)$ & Inferential statistic \\
\hline Age, years & $52.1(11.9) 35-74$ & $49.1(12.3) 35-74$ & $55.6(10.7) 38-72$ & $\mathrm{t}=1.6, \mathrm{p}>0.05$ \\
Gender, female, \% & 60 & 55 & 67 & $\chi^{2}=0.29, \mathrm{p}>0.05$ \\
Race, Black, \% & 88 & 89 & 88 & $\chi^{2}=0.34, \mathrm{p}>0.05$ \\
Months since transplant & $37.6(13.4) 8-71$ & $31.4(12.8) 18-71$ & $39.4(14.8) 8-66$ & $\mathrm{t}=96, \mathrm{p}>0.05$ \\
Diabetic, \% & 48 & 42 & 52 & $\chi^{2}=0.47, \mathrm{p}>0.05$ \\
Depression (BDI) & $11.1(9.3) 6-38$ & $10.5(10.2) 8-38$ & $11.8(8.4) 6-32$ & $\mathrm{t}=0.39, \mathrm{p}>0.05$ \\
\hline
\end{tabular}

Table 3. Group changes in adherence as measured by phone pill count and trough tacrolimus levels

\begin{tabular}{lccccc}
\hline Group & Baseline & Outcome & \% change from baseline & Statistic value & Group change comparison \\
\hline Pill count & & & & \\
$\quad$ Control & $94(0.05)$ & $94(0.05)$ & 0 & $\mathrm{t}=1.1, \mathrm{p}>0.05$ & $\mathrm{~F}(22,1)=12.005, \mathrm{p}=0.003^{*}$ \\
$\quad$ Intervention & $92(0.05)$ & $98(0.03)$ & 6.5 & $\mathrm{t}=2.2, \mathrm{p}=0.04^{*}$ & \\
Tacrolimus trough levels & & & $\mathrm{t}=1.5, \mathrm{p}>0.05$ & $\mathrm{~F}(22,1)=1.4, \mathrm{p}>0.05$ \\
$\quad$ Control & $7.3(3.5)$ & $6.4(3.5)$ & 12.3 & $\mathrm{t}=0.56, \mathrm{p}>0.05$ & \\
\multicolumn{2}{l}{ Intervention } & $5.4(2.8)$ & $5.7(1.8)$ & 5.5 &
\end{tabular}

* Significantly different $(\mathrm{p}<0.05)$.

\section{Results}

Baseline differences between those assigned to the treatment group and those assigned to the control group were evaluated (table 2). There were no significant between-group baseline differences in demographic, medical, or psychological variables ( $\mathrm{p}>0.05$, all cases). The sample's pre-treatment mean adherence score was $93 \%$ adherent (range 83-98).

The group scores on the self-report of depression (BDI) reflect a slight elevation of depressive affect and are consistent with our earlier work with kidney transplant recipients [33]. No adverse events were detected in either group over the course of the study.

\section{Adherence - Phone Pill Counts}

Based upon phone pill counts, there was a significant change in the intervention group mean adherence, which improved from 92 to $98 \%$, while there was no observable improvement in the control group (94-94\%; table 3). At study completion, the intervention group displayed significantly higher levels of adherence when compared to the control group $(\mathrm{t}=2.2, \mathrm{p}=0.04)$ and similarly, when the amount of change was compared between the groups, the intervention group showed more change than the control group $(\mathrm{F}(22,1)=12.005, \mathrm{p}=0.003)$.

Adherence Promotion

\section{Adherence Change - Tacrolimus Levels}

Mean tacrolimus trough levels did not differ significantly between groups either at baseline $(t=1.5, \mathrm{p}>0.05)$ or at study completion $(t=0.56, p>0.05)$. Neither group's mean tacrolimus trough levels changed significantly from baseline. Mean group levels were within target range $(5-15 \mu \mathrm{g} / \mathrm{l})$ at both measurement points. However, there was a substantive change in the SD of the trough levels when post-intervention values were compared to pre-intervention values. This change in the amount of statistical variability has been used as a measurement of adherence. In a study of pediatric liver transplant patients [66], a 1-point increase in the SD was associated with a 1.58 increase in hazard of graft loss. In this trial, the control group SD remained constant and the intervention group displayed a significant SD change (Levine's test, $<0.05$ ) with a full one point reduction.

\section{Discussion}

This study piloted the effectiveness of a group CBT/MI intervention on improving adherence to immunosuppressant medication in kidney transplant recipients. Significant improvement in our primary outcome measure, percent of pills taken, was demonstrated in our intervention group but not in our control condition, suggesting 
that this pilot adherence promotion program was successful at helping patients overcome barriers to nonadherence. The $6 \%$ increase in adherence not only has clinical significance, as it translates to about 2 doses in a 2 -week period (depending on the exact prescription), but also represents crossing the threshold to our a priori definition of 'adherent'. Furthermore, there was indication that the amount of variance in tacrolimus trough levels was decreased by the intervention. While there was no significant change in mean levels across treatment groups, as the means were within target range at all time points, the variability within that window decreased, suggesting more consistency in taking medication.

These results are of particular note because a primary focus of the transplant nephrology team is to promote the taking of prescribed medication as directed. Despite this high level of care and attention, there remains a substantive minority of patients that are nonadherent to their prescription. The clinical significance of this relatively low degree of nonadherence cannot be overestimated, as renal transplant patients who are not appropriately immunosuppressed run a substantial risk of rejection. While this trial was underpowered to examine the relationship between adherence and graft rejection, the magnitude of the improvement in percent of pills taken (6\% increase from baseline to follow-up in the intervention group) is also of true clinical significance. This intervention holds promise as a strategy to supplement standard care even for patients for whom traditional efforts have been unsuccessful.

The assessment of medication adherence is fraught with methodological challenges. In this pilot study, we demonstrate the feasibility and possible utility of unannounced phone pill counts as an alternative technique for measuring adherence. While it is possible that participants could adjust the numbers of pills counted to conceal missed doses, we had no indication that participants were attempting to guess the numbers of pills left from missed doses or any other mental calculation required for adjusting pill counts. Additionally, while it is possible that the phone assessments are, in and of themselves, an intervention, this does not seem to be the case. Lack of change in our control condition suggests that the measurement of medication adherence in this way does not interfere with regular medication-taking behavior, allowing the unannounced phone calls to serve as an unbiased assessment strategy.

While we believe that these preliminary results are meaningful, the study was conducted with a small sample from a single center and was of limited duration; because of these factors, we were unable to relate the change in medication taking to health changes or rejection markers. An additional limitation of the study is that we only partially described the psychosocial functioning of the participants. While we measured their baseline rates of depression, which were not clinically elevated or different across groups, we did not measure other potentially significant and influential psychosocial domains (e.g. coping strategies, rates of anxiety, health-related quality of life) [67-69].

The success of the intervention must also be appreciated in the context of the patient population. In this urban predominantly Black population, the reasons for noncompliance are complex and may well span systemic, social and individual parameters. However, in our preliminary work, 2 of the 3 most endorsed reasons for nonadherence were volitional. Both these factors highlight the need for further health education in this population as well as the potential benefit of further adherence promotion activities. Future research should explore the relevant psychosocial and behavioral factors in adherence behaviors, the overall utility of unannounced phone calls as an assessment strategy, and continue to focus resources on subpopulations that are greatly in need of support services.

\section{Acknowledgments}

D.C. and N.V.H. contributed to the study development, collected the data, performed statistical analysis, and prepared and reviewed the article. M.P., F.T. and M.S. consulted on study design and contributed to the preparation and review of the article.

\section{Funding}

This work was partially supported by an NIDDK grant (DK089149) to Dr. Daniel Cukor, as well as NIMHD funding to Dr. Moro Salifu and Dr. Daniel Cukor (MD006875).

\section{Disclosure Statement}

The authors of this manuscript have no conflicts of interest to disclose.

\section{Statement of Ethics}

This study was approved by the SUNY Downstate IRB and informed consent was documented for all participants.
Cukor/Ver Halen/Pencille/Tedla/Salifu 


\section{References}

1 Osterberg L, Blaschke T: Adherence to medi- 14 Butkus DE, Meydrech EF, Raju SS: Racial difcation. N Engl J Med 2005;353:487-497.

-2 Senst BL, Achusim LE, Genest RP, Cosentino LA, Ford CC, Little JA, Raybon SJ, Bates DW: Practical approach to determining costs and frequency of adverse drug events in a health care network. Am J Health Syst Pharm 2001; 58:1126-1132.

3 Schiff GD, Fung S, Speroff T, McNutt RA: Decompensated heart failure: symptoms, patterns of onset, and contributing factors. Am J Med 2003;114:625-630.

-4 Yen EF, Hardinger K, Brennan DC, Woodward RS, Desai NM, Crippin JS, Gage BF, Schnitzler MA: Cost-effectiveness of extending Medicare coverage of immunosuppressive medications to the life of a kidney transplant. Am J Transplant 2004;4:1703-1708.

5 Matas AJ, Humar A, Gillingham KJ, Payne WD, Gruessner RW, Kandaswamy R, Dunn DL, Najarian JS, Sutherland DE: Five preventable causes of kidney graft loss in the 1990s: a single-center analysis. Kidney Int 2002;62: 704-714.

-6 Gaston RS, Hudson SL, Ward M, Jones P, Macon R: Late renal allograft loss: noncompliance masquerading as chronic rejection. Transplant Proc 1999;31:21S-23S.

7 Dobbels F, De Geest S, Van Cleemput J, Droogne W, Vanhaecke J: Effect of late medication non-compliance on outcome after heart transplantation: a 5-year follow-up. J Heart Lung Transplant 2004;23:1245-1251.

$\checkmark 8$ Wolfe RA, Ashby VB, Milford EL, Ojo AO, Ettenger RE, Agodoa LY, Held PJ, Port FK: Comparison of mortality in all patients on dialysis, patients on dialysis awaiting transplantation, and recipients of a first cadaveric transplant. N Engl J Med 1999;341:1725-1730.

-9 Jindal RM, Joseph JT, Morris MC, Santella RN, Baines LS: Noncompliance after kidney transplantation: a systematic review. Transplant Proc 2003;35:2868-2872.

$\checkmark 10$ Butler JA, Peveler RC, Roderick P, Horne R, Mason JC: Measuring compliance with drug regimens after renal transplantation: comparison of self-report and clinician rating with electronic monitoring. Transplantation 2004; 77:786-789.

11 Dew MA, DiMartini AF, De Vito Dabbs A, Myaskovsky L, Steel J, Unruh M, Switzer GE, Zomak R, Kormos RL, Greenhouse JB: Rates and risk factors for nonadherence to the medical regimen after adult solid organ transplantation. Transplantation 2007;83:858-873.

12 Didlake RH, Dreyfus K, Kerman RH, Van Buren CT, Kahan BD: Patient noncompliance: a major cause of late graft failure in cyclosporine-treated renal transplants. Transplant Proc 1988;20(3 suppl 3):63-69.

\13 Chisholm MA, Mulloy LL, Jagadeesan M, DiPiro JT: Impact of clinical pharmacy services on renal transplant patients' compliance with immunosuppressive medications. Clin Transplant 2001;15:330-336. ferences in the survival of cadaveric renal allografts. Overriding effects of HLA matching and socioeconomic factors. N Engl J Med 1992;327:840-845.

15 Chisholm MA, Kwong WJ, Spivey CA: Associations of characteristics of renal transplant recipients with clinicians' perceptions of adherence to immunosuppressant therapy. Transplantation 2007;84:1145-1150.

16 Denhaerynck K, Steiger J, Bock A, SchäferKeller P, Köfer S, Thannberger N, De Geest S: Prevalence and risk factors of non-adherence with immunosuppressive medication in kidney transplant patients. Am J Transplant 2007;7:108-116.

17 Kiley DJ, Lam CS, Pollak R: A study of treatment compliance following kidney transplantation. Transplantation 1993;55:51-56.

18 Rosenberger J, Geckova AM, van Dijk JP, Nagyova I, Roland R, van den Heuvel WJ, Groothoff JW: Prevalence and characteristics of noncompliant behaviour and its risk factors in kidney transplant recipients. Transpl Int 2005;18:1072-1078.

19 Schweizer RT, Rovelli M, Palmeri D, Vossler E, Hull D, Bartus S: Noncompliance in organ transplant recipients. Transplantation 1990; 49:374-377.

20 Siegal BR, Greenstein SM: Postrenal transplant compliance from the perspective of African-Americans, Hispanic-Americans, and Anglo-Americans. Adv Ren Replace Ther 1997;4:46-54.

21 Weng FL, Israni AK, Joffe MM, Hoy T, Gaughan CA, Newman M, Abrams JD, Kamoun M, Rosas SE, Mange KC, Strom BL, Brayman KL, Feldman HI: Race and electronically measured adherence to immunosuppressive medications after deceased donor renal transplantation. J Am Soc Nephrol 2005; 16:1839-1848.

22 De Geest S, Borgermans L, Gemoets H, Abraham I, Vlaminck H, Evers G, Vanrenterghem $\mathrm{Y}$ : Incidence, determinants, and consequences of subclinical noncompliance with immunosuppressive therapy in renal transplant recipients. Transplantation 1995;59:340-347.

23 Frazier P, Davis-Ali SH, Dahl KE: Correlates of noncompliance among renal transplant recipients. Clin Transplant 1994;8:550-557.

24 Greenstein S, Siegal B: Compliance and noncompliance in patients with a functioning renal transplant: a multicenter study. Transplantation 1998;66:1718-1726.

25 Chisholm MA, Lance CE, Mulloy LL: Patient factors associated with adherence to immunosuppressant therapy in renal transplant recipients. Am J Health Syst Pharm 2005;62: 1775-1781.

26 Chisholm MA, Lance CE, Williamson GM, Mulloy LL: Development and validation of the immunosuppressant therapy adherence instrument (ITAS). Patient Educ Couns 2005; 59:13-20.
27 Saha S, Freeman M, Toure J, Tippens KM, Weeks C: Racial and Ethnic Disparities in the VA Healthcare System: A Systematic Review. Washington, Department of Veterans Affairs (US), 2007, pp 423-431.

28 Becker MH, Radius SM, Rosenstock IM, et al: Compliance with a medical regimen for asthma: a test of the health belief model. Public Health Rep 1978;93:268-277.

29 Carpenter CJ: A meta-analysis of the effectiveness of health belief model variables in predicting behavior. Health Commun 2010; 25:661-669.

30 Jones CJ, Smith H, Llewellyn C: Evaluating the effectiveness of health belief model interventions in improving adherence: a systematic review. Health Psychol Rev 2014;8:253-269.

- 31 Resnicow K, Jackson A, Wang T, De AK, McCarty F, Dudley WN, Baranowski T: A motivational interviewing intervention to increase fruit and vegetable intake through Black churches: results of the eat for life trial. Am J Public Health 2001;91:1686-1693.

32 Resnicow K, Baranowski T, Ahluwalia JS, Braithwaite RL: Cultural sensitivity in public health: defined and demystified. Ethn Dis 1999;9:10-21.

- 33 Gordon EJ, Gallant M, Sehgal AR, Conti D, Siminoff LA: Medication-taking among adult renal transplant recipients: barriers and strategies. Transpl Int 2009;22:534-545.

34 Constantiner M, Cukor D: Barriers to immunosuppressive medication adherence in highrisk adult renal transplant recipients. Dial Transplant 2011;40:60-66.

35 Rosenthal Asher D, Ver Halen N, Cukor D: Depression and nonadherence predict mortality in hemodialysis treated end-stage renal disease patients. Hemodial Int 2012;16:387393.

36 Haynes RB, Ackloo E, Sahota N, McDonald HP, Yao X: Interventions for enhancing medication adherence. Cochrane Database Syst Rev 2008;2:CD000011.

37 De Bleser L, Matteson M, Dobbels F, Russell C, De Geest S: Interventions to improve medication-adherence after transplantation: a systematic review. Transpl Int 2009;22:780-797.

38 Low JK, Williams A, Manias E, Crawford K: Interventions to improve medication adherence in adult kidney transplant recipients: a systematic review. Nephrol Dial Transplant 2014;30:752-761.

39 Garcia MF, Bravin AM, Garcia PD, Contti MM, Nga HS, Takase HM, de Andrade LG: Behavioral measures to reduce non-adherence in renal transplant recipients: a prospective randomized controlled trial. Int Urol Nephrol 2015;47:1-7.

- 40 De Geest S, Schäfer-Keller P, Denhaerynck K, Thannberger N, Köfer S, Bock A, Surber C, Steiger J: Supporting medication adherence in renal transplantation (SMART): a pilot RCT to improve adherence to immunosuppressive regimens. Clin Transplant 2006;20:359-368. 
-41 Russell C, Conn V, Ashbaugh C, Madsen R, Wakefield M, Webb A, Coffey D, Peace L: Taking immunosuppressive medications effectively (TIMELink): a pilot randomized controlled trial in adult kidney transplant recipients. Clin Transplant 2011;25:864-870.

42 Russell CL: Culturally responsive interventions to enhance immunosuppressive medication adherence in older African American kidney transplant recipients. Prog Transplant 2006;16:187-195; quiz 196.

-43 Chisholm MA, Lance CE, Williamson GM, Mulloy LL: Development and validation of an immunosuppressant therapy adherence barrier instrument. Nephrol Dial Transplant 2005;20:181-188.

44 Vrijens B, De Geest S, Hughes DA, Przemyslaw K, Demonceau J, Ruppar T, Dobbels F, Fargher E, Morrison V, Lewek P, Matyjaszczyk M, et al: A new taxonomy for describing and defining adherence to medications. Br J Clin Pharmacol 2012;73:691-705.

45 Thompson N, Nazir N, Cox LS, et al: Unannounced telephone pill counts for assessing varenicline adherence in a pilot clinical trial. Patient Prefer Adherence 2011;5:475-482.

46 Bangsberg DR: Monitoring adherence to HIV antiretroviral therapy in routine clinical practice: the past, the present, and the future. AIDS Behav 2006;10:249-251.

-47 Loghman-Adham M: Medication noncompliance in patients with chronic disease: issues in dialysis and renal transplantation. Am J Manag Care 2003;9:155-171.

- 48 Rudd P, Byyny RL, Zachary V, et al: Pill count measures of compliance in a drug trial: variability and suitability. Am J Hypertens 1988; 1(3 pt 1):309-312.

-49 van Onzenoort HA, Verberk WJ, Kessels AG, et al: Assessing medication adherence simultaneously by electronic monitoring and pill count in patients with mild-to-moderate hypertension. Am J Hypertens 2010;23:149154.

50 Kalichman SC, Amaral CM, Stearns H, White D, Flanagan J, Pope H, Cherry C, Cain D, Ea- ton L, Kalichman MO: Adherence to antiretroviral therapy assessed by unannounced pill counts conducted by telephone. J Gen Intern Med 2007;22:1003-1006.

51 Kalichman SC, Amaral CM, Cherry C, Flanagan J, Pope H, Eaton L, Kalichman MO, Cain D, Detorio M, Caliendo A, Schinazi RF: Monitoring medication adherence by unannounced pill counts conducted by telephone: reliability and criterion-related validity. HIV Clin Trials 2008;9:298-308.

52 Bangsberg DR, Hecht FM, Charlebois ED, Chesney M, Moss A: Comparing objective measures of adherence to HIV antiretroviral therapy: electronic medication monitors and unannounced pill counts. AIDS Behav 2001; 5:275-281.

53 Ihara H, Shinkuma D, Ichikawa Y, Nojima M, Nagano S, Ikoma F: Intra- and interindividual variation in the pharmacokinetics of tacrolimus (FK506) in kidney transplant recipients - importance of trough level as a practical indicator. Int J Urol 1995;2:151-155.

54 Beck AT, Steer RA, Carbin MG: Psychometric properties of the beck depression inventory: twenty-five years of evaluation. Clin Psy Rev 1988;8:77-100.

55 Pinsky BW, Takemoto SK, Lentine KL, Burroughs TE, Schnitzler MA, Salvalaggio PR: Transplant outcomes and economic costs associated with patient noncompliance to immunosuppression. Am J Transplant 2009;9: 2597-2606.

56 Nevins TE, Kruse L, Skeans MA, Thomas W: The natural history of azathioprine compliance after renal transplantation. Kidney Int 2001;60:1565-1570.

57 Takemoto SK, Pinsky BW, Schnitzler MA, et al: A retrospective analysis of immunosuppression compliance, dose reduction and discontinuation in kidney transplant recipients. Am J Transplant 2007;7:27042711.

58 Schäfer-Keller P, Steiger J, Bock A, Denhaerynck K, De Geest S: Diagnostic accuracy of measurement methods to assess non-ad- herence to immunosuppressive drugs in kidney transplant recipients. Am J Transplant 2008;8:616-626.

59 Beck AT: The current state of cognitive therapy: a 40-year retrospective. Arch Gen Psychiatry 2005;62:953-959.

60 Meichenbaum D: Cognitive behaviour modification. Cognitive Behav Ther 1977;6:185192.

61 Beck JS: Cognitive Behavior Therapy: Basics and Beyond. Guilford Press, 2011

62 Rollnick S, Miller WR, Butler CC: Motivational Interviewing in Health Care: Helping Patients Change Behavior. New York, The Guilford Press, 2008.

- 63 Rubak S, Sandbaek A, Lauritzen T, Christensen B: Motivational interviewing: a systematic review and meta-analysis. Br J Gen Pract 2005;55:305-312.

64 Burke BL, Arkowitz H, Menchola M: The efficacy of motivational interviewing: a metaanalysis of controlled clinical trials. J Consult Clin Psychol 2003;71:843-861.

65 Freedland KE, Mohr DC, Davidson KW, Schwartz JE: Usual and unusual care: existing practice control groups in randomized controlled trials of behavioral interventions. Psychosom Med 2011;73:323-335.

66 Pollock-BarZiv SM, Finkelstein Y, Manlhiot C, Dipchand AI, Hebert D, Ng VL, Solomon M, McCrindle BW, Grant D: Variability in tacrolimus blood levels increases the risk of late rejection and graft loss after solid organ transplantation in older children. Pediatr Transplant 2010;14:968-975.

67 Chisholm MA: Enhancing transplant patients' adherence to medication therapy. Clin Transplant 2002;16:30-38.

68 Muehrer RJ, Becker BN: Life after transplantation: new transitions in quality of life and psychological distress. Semin Dial 2005;18: 124-131.

69 Wainwright SP, Fallon M, Gould D: Psychosocial recovery from adult kidney transplantation: a literature review. J Clin Nurs 1999;8: 233-245. 